\title{
Use of impella for off pump myocardial revascularization in high risk patients
}

\author{
Paolo Pepino ${ }^{1 *}$, Germano Coronella ${ }^{1}$, Salvatore Giordano ${ }^{1}$, Raffaela Provenzano ${ }^{1}$, Agostino La Marca², \\ Mario Monaco ${ }^{2}$, Arturo Giordano ${ }^{3}$ \\ From World Society of Cardiothoracic Surgeons 25th Anniversary Congress, Edinburgh \\ Edinburgh, UK. 19-22 September 2015
}

\section{Background/Introduction}

Patients undergoing coronary surgery are changed in the last years becoming a challenge for the cardiac surgeon not only for the quality of the coronary artery involved in the disease but also for the quality of patients. Low ejection fraction, elderly, COPD, kidney failure, Diabetes are often found in patients with coronary artery disease undergoing CABG.

\section{Aims/Objectives}

Beating heart myocardial revascularization is a wellestablished surgical technique but in case of very low EF (below 30\%) there is a particular high surgical risk of conversion to on-pump surgery. The recently developed of Impella device (Abiomed, Danvers, MA) represent a compromise between circulatory support and limited invasiveness.

\section{Method}

Three patients, male, admitted for acute coronary syndrome with three vessels CAD and low ejection fraction below $30 \%$, were operated in our department. After preliminary lower limb duplex ultrasound to exclude peripheral artery disease, an Impella Recover LP 5.0 device was inserted via surgical exposure of the right femoral artery in one case and an Impella recover LP 4,5 via percutaneous insertion of the femoral artery in two cases.

\section{Results}

The myocardial revascularization was performed using a complete arterial revascularization: Left internal mammary artery on the LAD and the radial artery "T" anastomosed from the LIMA to the other vessels (diagonal, intermedius

${ }^{1}$ Department of Cardiothoracic Surgery, Presidio Ospedaliero Pineta Grande, Castel Volturno, Caserta, Italy

Full list of author information is available at the end of the article ramus, OM and PDA). The device was left in for 48 Hours after the operation. All patients were discharged home after 9-10 days after admission and a follow up echocardiography performed six month after the operation showed an increase of the ejection fraction up to $40-45 \%$.

\section{Discussion/Conclusion}

Use of the Impella Recover device for patients undergoing off pump CABG is feasible and safe, and appears a promising strategy to improve short- and long-term outcomes.

\section{Authors' details}

'Department of Cardiothoracic Surgery, Presidio Ospedaliero Pineta Grande, Castel Volturno, Caserta, Italy. ${ }^{2}$ Department of Vascular Surgery, Presidio Ospedaliero Pineta Grande, Castel Volturno, Caserta, Italy. ${ }^{3}$ Department of Invasive Cardiology, Presidio Ospedaliero Pineta Grande, Castel Voturno, Caserta, Italy.

Published: 16 December 2015

doi:10.1186/1749-8090-10-S1-A160

Cite this article as: Pepino et al.: Use of impella for off pump myocardial revascularization in high risk patients. Journal of Cardiothoracic Surgery 2015 10(Suppl 1):A160.

Submit your next manuscript to BioMed Central and take full advantage of:

- Convenient online submission

- Thorough peer review

- No space constraints or color figure charges

- Immediate publication on acceptance

- Inclusion in PubMed, CAS, Scopus and Google Scholar

- Research which is freely available for redistribution 